\title{
Optimization of intercept parking lots
}

\author{
Tatyana Simankina ${ }^{1, *}$, Vitaly Lukinov ${ }^{2}$ and Denis Davydov ${ }^{3}$ \\ ${ }^{1}$ Peter the Great St. Petersburg Polytechnic University, 29, Polytechnicheskaya, 195251, \\ St. Petersburg, Russia \\ ${ }^{2}$ Moscow State University of Civil Engineering, 26, Yaroslavskoye shosse, Moscow, 129337, Russia \\ ${ }^{3}$ Plekhanov Russian University of Economics, Stremyanny lane 36, Moscow, 117997, Russia
}

\begin{abstract}
The paper discusses the main prerequisites for the development of parking lots. The main problems are estimated, the solution of which is the construction of multi-level intercept parking lots. The urgency of the problem is associated with the increasing gas pollution in the city, an increase in the number of accidents, a decrease in the speed of delivery of goods and the availability of parking spaces in the city center. The parking lot is considered, which provides its functions all year round regardless of weather conditions. At the same time, design solutions and materials were selected to minimize financial costs. The use of steel as the main material for supporting structures makes it possible to reduce the cost of construction. Structural columns, vertical ties and beams are made from it. Floor slabs should be made of reinforced concrete on fixed formwork from galvanized corrugated sheet of various grades. When using sheets with a high corrugation, it is possible to create a ceiling without secondary beams. Staircases, stairways and elevator shafts should also be made from reinforced concrete or from concrete blocks in order to achieve the required fire resistance limit corresponding to that required for parking lot. The appearance of the multi-level intercept parking lot meets modern aesthetic requirements and also has a positive effect on the minds of motorists, appearing as part of a comfortable living environment.
\end{abstract}

\section{Introduction}

The relevance of the construction of intercept parking lots is substantiated by a sharp increase in the number of personal vehicles over the past decade (Fig. 1). An analysis of traffic situations in the largest cities of the world, including St. Petersburg, shows that there are no cities that do not face the problem of traffic congestion. In the morning and evening rush hours, the streets of the central districts of St. Petersburg are a big problem for many motorists, the central areas of the city are packed with cars.

\footnotetext{
*Corresponding author: p198320@yandex.ru
} 


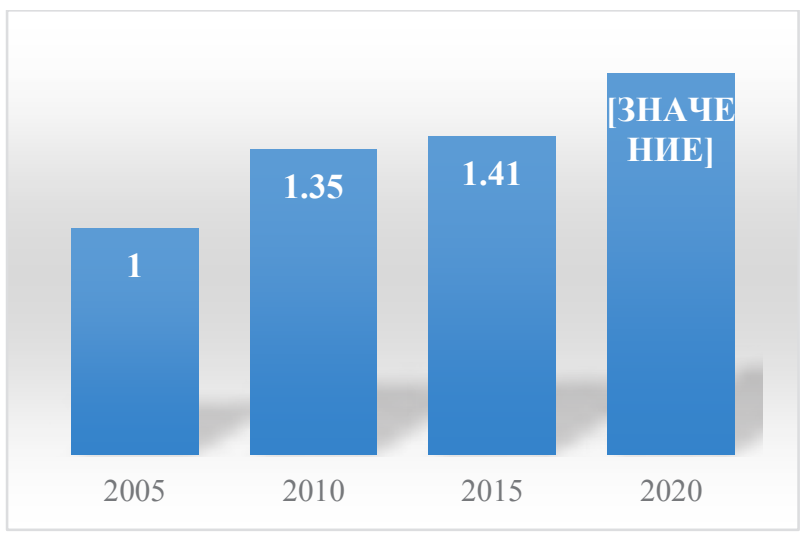

Fig. 1. Dynamics of changes in the number of personal vehicles (million items) in St. Petersburg.

In addition, a large number of cars are located on sidewalks, lawns, or even in parks, which interferes with the passage of pedestrians, and are also located along the roads, creating problems for working special vehicles.

In addition to traffic jams, congestion and the threat of loss of the humanitarian-oriented appearance of urban areas associated with their excessive saturation with cars, the environmental side of the issue is also important. [1]

In St. Petersburg, in order to unload the transport network of the city, there is a network of intercept parking lots located near metro stations. However, due to the high growth rate of cars, the number of available parking spaces is not enough today, and motorists are forced to leave their cars in places that are not intended for this or continue to move around the city by car.

These and other problems lead to the search for new solutions for organizing parking space for motorists who want to leave their cars near metro stations or at major transport hubs and continue to move on public transport.

One of the ways to solve this problem is to create a network of multi-level intercept parking lots, capable of "intercepting" a significant number of cars in order to improve the ecological situation and resolve the current situation with traffic jams.

Analysis of international experience in the construction of multi-level parking lots shows the feasibility of implementing such projects. Thus, in 2015, the construction of 13 facilities was completed in Malaysia, which in total can fit up to seven thousand cars. The most striking example was the project of a six-story intercept parking lot at Gombak station, which can simultaneously accommodate 1,260 vehicles, while in the past there was space for only 471 vehicles (Fig. 2). The parking lot alone helped to reduce the load on the transport network. [2]

Another example of the successful use of available floor space is the construction of a multi-storey structure in Gibraltar, UK (Figure 3). The intercept parking lot can accommodate up to 1000 cars at a time, which allows freeing narrow streets from a large number of cars and preserving the unique nature of the peninsula from harmful emissions. [2] 


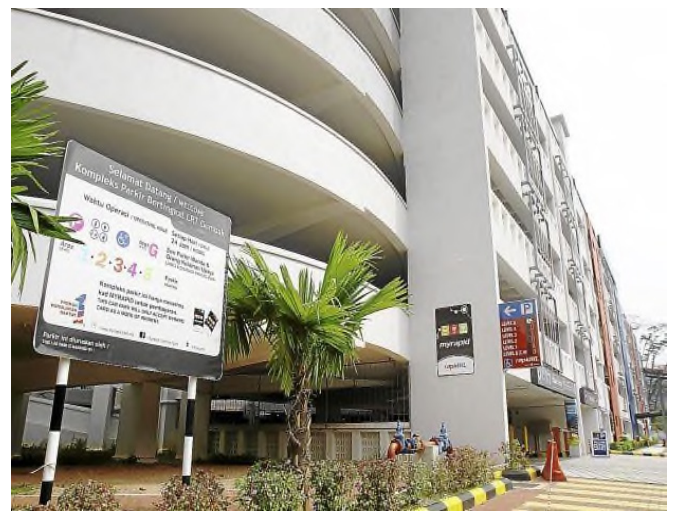

Fig. 2. Six-story intercept parking lot in Malaysia.

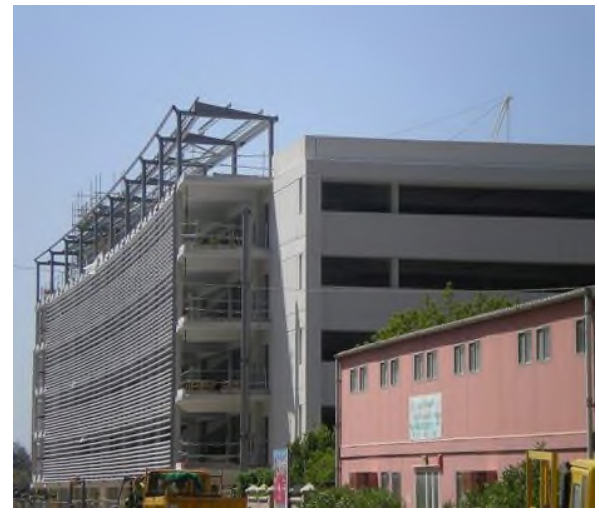

Fig. 3. Multi-level intercept parking for 1000 spaces in Gibraltar, UK.

\section{Methods}

The paper uses a method to optimize the choice of a multi-level intercept parking project as one of the ways to develop the infrastructure of a metropolis.

At the moment, there are uncontrollable parking lots on the territory under consideration, which are used as intercepting ones, with a total of about 200 cars, excluding cars located in the territories adjacent to this site.

The site is located in the area of high-speed roads and highways with the inclusion of transport infrastructure, where it is allowed to place permanent or temporary garages with several parking spaces, parking lots, garages, including multi-storey ones.

The use of steel structures as a supporting frame allows saving up to $30 \%$ on foundation construction due to a significant reduction in the load transmitted to the mat. Comparison of the weight indicators of the corresponding elements for two options of structures of a fivestorey parking garage with the same dimensions of storage and passage of cars are given in the table [3], from which it follows that the load from steel structures is almost 2.5 times less than from reinforced concrete ones.

Therefore, the use of steel as the main material for supporting structures seems to be more promising. Structural columns, vertical ties and beams are made from it. Floor slabs are made of reinforced concrete on fixed formwork from galvanized corrugated sheet of various grades. When using sheets with a high corrugation, it is possible to create a ceiling without secondary beams. Staircases, stairways and elevator shafts should also be made from reinforced concrete or from concrete blocks in order to achieve the required fire resistance limit corresponding to that required for parking lot, as well as for resistance to salt solutions used in winter.

Thus, the optimal model of a multi-level intercept parking lot is a parking lot with a steel frame and a reinforced concrete slab over a non-removable formwork that meets the requirements [4].

\section{Results}

Using the criterion of minimum costs, taking into account the constraints associated with the required number of parking spaces, with a limited parking area, taking into account the higher cost of underground parking and the need to protect the parking area from snow, an optimal option was obtained. 
The multi-level intercept parking is a four-storey open-type structure with a floor height of $3 \mathrm{~m}$. The dimensions in the axes are $35.7 \times 54.92 \mathrm{~m}$. The total occupied area is $1988 \mathrm{~m}^{2}$.

One floor can accommodate 62 cars. The dimensions of the parking space are $5460 \times 2595 \mathrm{~mm}$. Cars are parked perpendicular to the passage on both sides. There is oneway circular traffic in the parking lot (Fig. 4).

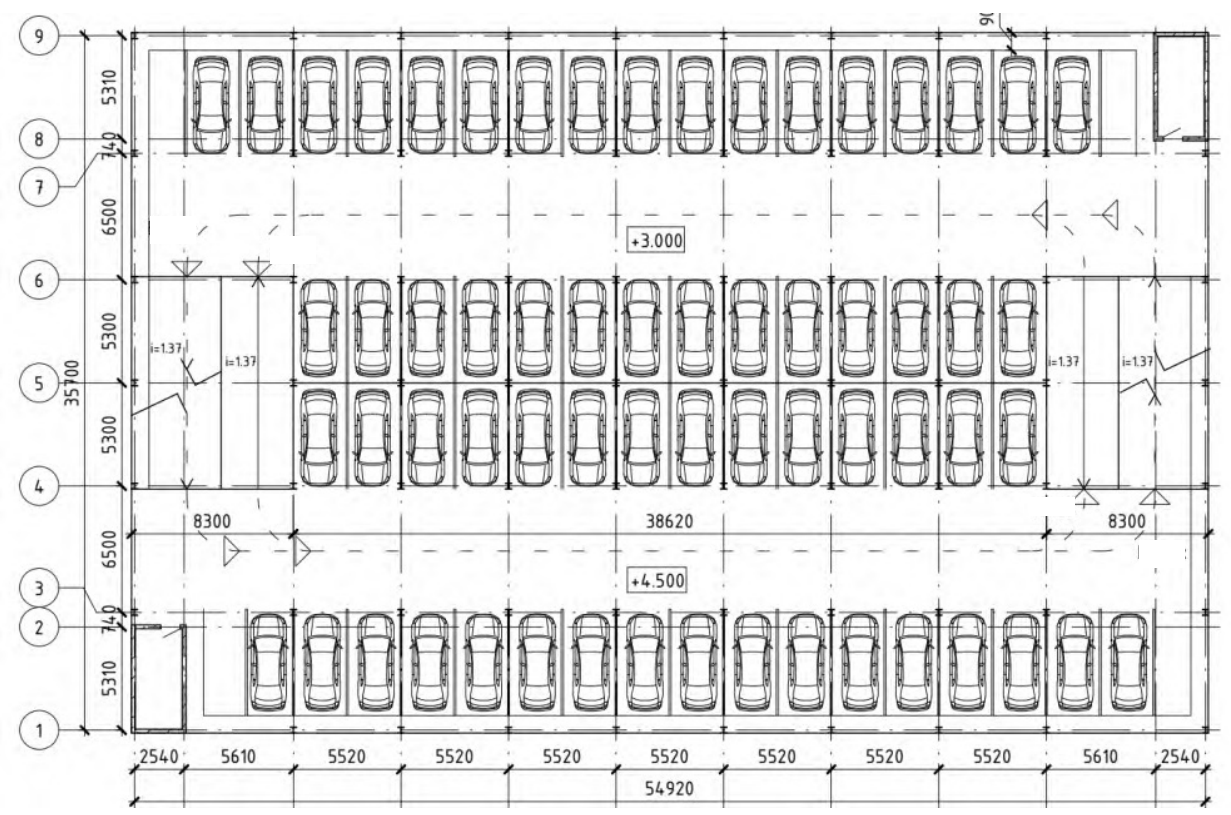

Fig. 4. Plan of a typical floor.

Based on the analysis $[5,6]$, we take the construction cost of $1 \mathrm{~m}^{2}-\$ 183$, then the cost of building a four-story intercept parking lot on a metal frame:

$248 \mathrm{~m} / \mathrm{m} \times 28.1 \mathrm{~m}^{2} \times 183=\$ 1275290$.

Thus, the estimated cost of construction and equipment of a four-storey multi-level intercept parking lot on a metal frame for 248 parking spaces will amount to $\$ 1275.3$ thousand.

The appearance of multi-level intercept parking lots is dictated by the existing surrounding buildings. Parking should not dominate against the background of other, no less significant, objects. Also, do not forget about the humanistic and artistic aspects in the formation of a person's material environment. The appearance of a multi-level intercept parking lot, first of all, should not be repulsive, it should meet modern aesthetic requirements, as well as positively influence the minds of motorists, appearing as part of a comfortable living environment. [7, 8]

An example of the appearance of a multi-level intercept parking lot is considered. The architectural appearance of the parking lot should be aligned with the appearance of the existing buildings in the area (Fig. 5). 


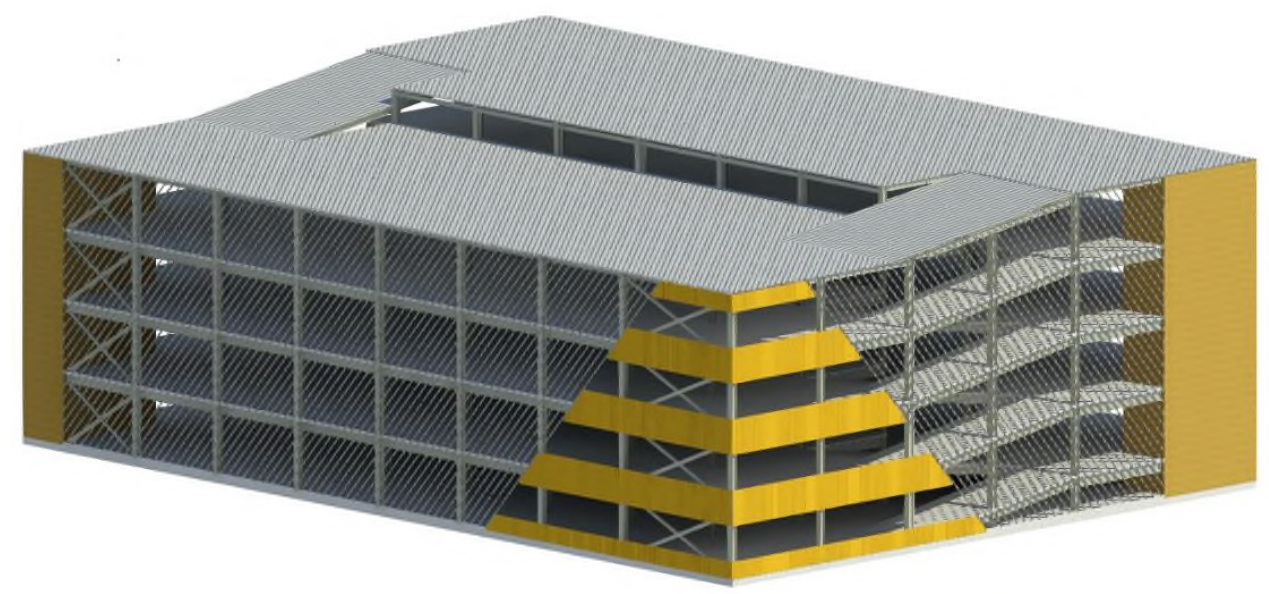

Fig. 5. The architectural appearance of a multi-level intercept parking lot.

\section{Conclusions}

The considered option of a multi-level intercept parking lot is the optimal solution for the criterion of minimizing costs in limited urban areas with a significantly increasing density of traffic flows. When implementing projects for the construction of such parking lots, problems associated with the increasing gas pollution of the city, an increase in the number of accidents, a decrease in the speed of delivery of goods and the availability of parking spaces in the city center can be reduced.

\section{References}

1. N.N. Antonova, S.V. Vorontsov, Architecture. Construction. Education, 96-107 (2015)

2. S.V. Erzakov, M.A. Korenevskaya, Regional aspects of the development of science and education in the field of architecture, construction, land management and cadastre at the beginning of the III millennium. KnASTU, 450-456 (2018)

3. P.G. Eremeev, Industrial and civil engineering 3(17), 19-21 (2007)

4. K.V. Soloviev, A.R. Kuzminykh, Synergy of Sciences 12, 801-812 (2017)

5. O.N. Popova, K. Martynov, R. Husnutdinov, IOP Conf. Series: Earth and Environmental Science 90, 012225 (2017) doi: 10.1088/1755-1315/90/1/012225

6. I. Duvanova, T. Bubnova, M. Romanovich, Procedia Engineering 165, 1794-1800 (2016) DOI: https://doi.org/10.1016/j.proeng.2016.11.924

7. I.A. Duvanova, T.L. Simankina, Construction of unique buildings and structures 2(41), 108-117 (2016)

8. I. Duvanova, T. Simankina, A. Shevchenko, T. Musorina, A. Yufereva Procedia Engineering 165, 1784-1793 (2016) 